\title{
Transplante de células da medula óssea no tratamento da cardiopatia chagásica crônica
}

\author{
Bone marrow cells transplant in the treatment \\ of chronic chagasic cardiomyopathy
}

\author{
Ricardo Ribeiro dos Santos ${ }^{1,2}$, Milena Botelho Pereira Soares ${ }^{1,2}$ \\ e Antônio Carlos Campos de Carvalho ${ }^{2,3}$
}

\begin{abstract}
RESUMO
A cardiopatia chagásica crônica é ainda uma das maiores causas de óbito por insuficiência cardíaca na América Latina e para a qual não há nenhum tratamento eficaz até o momento. Enquanto a população de indivíduos com doença de Chagas aguarda o desenvolvimento de novos quimioterápicos mais eficientes e de menor toxicidade para a eliminação do Trypanosoma cruzi, uma nova estratégia surgiu na tentativa de reparar ou diminuir os danos causados ao miocárdio de pacientes com forma crônica cardíaca. Trata-se do transplante de células de medula óssea obtidas do próprio indivíduo a ser tratado, que pode levar à melhora funcional e da qualidade de vida dos pacientes, como ocorreu em estudos utilizando esta abordagem para o tratamento de pacientes com insuficiência cardíaca de etiologia isquêmica. Os possíveis efeitos de terapias celulares e sua utilização em pacientes cardiopatas chagásicos crônicos são discutidos no presente artigo.
\end{abstract}

Palavras-chaves: Doença de Chagas. Cardiopatia. Células-tronco. Medula óssea. Transplante autólogo.

\begin{abstract}
Chronic chagasic cardiomyopathy remains a major cause of death due to heart failure in Latin American countries and for which there is currently no effective treatment. While chagasic patients wait for the development of more efficient and less toxic chemotherapeutics for the elimination of Trypanosoma cruzi, a new strategy has appeared in an attempt to repair or ameliorate the damage caused to the myocardium of patients with chronic chagasic cardiomyopathy. This therapy, involving the transplant of bone marrow cells obtained from the patient to be treated, may lead to improvement in heart function and in life quality of patients with severe chagasic cardiopathy, similar to that obtained with this approach in the treatment of patients with heart failure of ischemic etiology. The possible effects of cell therapies and its applications in chronic chagasic cardiopaths are discussed in the present report.
\end{abstract}

Key-words: Chagas' disease. Cardiomyopathy. Stem cells. Bone marrow. Autologous transplant.

Nos últimos anos, uma nova área da medicina vem sendo desenvolvida, que abre perspectivas inovadoras para 0 tratamento de doenças crônico-degenerativas. É a chamada medicina regenerativa e consiste na utilização de células, fatores de proliferação e diferenciação celulares e biomateriais que permitem ao próprio organismo reparar tecidos e órgãos lesados. Alguns dos alvos terapêuticos são órgãos considerados por muito tempo como incapazes de desenvolver quaisquer processos de regeneração, como 0 cérebro e 0 coração. Os relatos de demonstrações de que os tecidos adultos possuem células-tronco pluripotentes próprias ${ }^{19} 15$, de que há migração de células-tronco do sangue periférico e sua diferenciação para tipos celulares residentes em órgãos como 0 coraçãa ${ }^{16}$ e de que células já diferenciadas podem proliferar em resposta a agressões teciduais ${ }^{10}$ têm sido cada vez mais freqüentes na literatura, e indicam que 0 processo de regeneração ocorre nestes tecidos,

1. Centro de Pesquisas Gonçalo Moniz da Fundação Oswaldo Cruz, Salvador, BA. 2. Instituto do Milênio de Bioengenharia Tecidual do Ministério da Ciência e Tecnologia, Brasília, DF. 3. Instituto de Biofísica Carlos Chagas Filho da Universidade Federal do Rio de Janeiro, RJ.

Auxílio financeiro: Instituto do Milênio de Bioengenharia Tecidual (IMBT/MCT), CNPq, FIOCRUZ e NIH HL073732-01.

Endereço para correspondência: Dr. Ricardo Ribeiro dos Santos. Laboratório de Engenharia Tecidual e Imunofarmacologia/CPqGM/FIOCRUZ. Rua Waldemar Falcão 121, Brotas, 40295-001 Salvador, BA, Brasil.

Tel: 71 356-4320 r: 260/272, Fax: 71 356-4320 r: 292

e-mail: ricardoribeiro@ cpqgm.fiocruz.br

Recebido para publicação em 5/1/2004

Aceito em 13/8/2004 
embora possa não ser eficiente para levar à cura dependendo do grau de dano tecidual que tenha ocorrido. Este é 0 caso do infarto do miocárdio, onde uma baixa taxa de proliferação de mioblastos e cardiomiócitos pode ser detectada nas bordas das lesões, porém não o suficiente para reparar todo o dano tecidual causado pela isquemia, resultando em extensas áreas de fibrose.

\section{CÉLULAS-TRONCO}

A célula-tronco é uma célula indiferenciada, capaz de proliferar e de originar outras células-tronco ( 0 que é denominado autoregeneração) e células com capacidade de se diferenciar, originando células diferenciadas com capacidade funcional normal. Para realizar a dupla tarefa de se auto-regenerar e ao mesmo produzir células diferenciadas, a célula-tronco pode seguir dois modelos básicos de divisão celular. 0 determinístico, onde a divisão de uma célula-tronco gera invariavelmente uma nova célulatronco e uma célula que irá se diferenciar; ou 0 aleatório ou estocástico, onde algumas células-tronco geram apenas novas células-tronco ao se dividirem, enquanto outras geram apenas células com potencial para sofrer diferenciação.

\section{CÉLULAS-TRONCO EMBRIONÁRIAS}

Em 1981, foi descrita a técnica de imortalização de células derivadas da massa celular interna de blastocistos de embriões de camundongos, as células-tronco embrionárias ou ES (embryonic stem cells) ${ }^{4}$. Células ES são pluripotentes, pois podem proliferar indefinidamente in vitro sem se diferenciar, mas também podem se diferenciar em vários tipos celulares dependendo das condições de cultivo. Outra característica especial destas células é que elas podem ser re-introduzidas em embriões de camundongos, dando origem a células em todos os tecidos do animal adulto, inclusive a células germinativas ${ }^{17}$. 0 fato das células ESse integrarem em todos os tecidos do animal adulto quando re-introduzidas em embriões de camundongo demonstra 0 seu potencial de diferenciação em qualquer célula do organismo, de uma célula da pele a um neurônio. Vários estudos demonstraram a diferenciação das células ES de camundongos em tipos celulares distintos em culturas in vitro, gerando células hematopoiéticas, neurônios, astrócitos e oligodendrócitos, dentre outras ${ }^{21}$. Aidentificação dos fatores que levam ao direcionamento deste processo de diferenciação permitirá que, a partir de células-tronco embrionárias, possamos cultivar de forma controlada os mais diferentes tipos celulares, abrindo a possibilidade de expandir ou construir in vitro tecidos e órgãos, tornando viável a bioengenharia tecidual.

\section{CÉLULAS-TRONCO NOS ORGANISMOS ADULTOS}

Desde a década de 60, sabe-se que organismos adultos têm a capacidade de auto-regenerar determinados tecidos como a pele, 0 epitélio intestinal e principalmente 0 sangue, que tem suas células constantemente destruídas e renovadas, num complexo e finamente regulado processo de proliferação e diferenciação celular. Durante muitas décadas estudou-se o processo de hematopoiese a partir de células-tronco multipotentes de medula óssea, que são capazes de dar origem a células progressivamente mais diferenciadas e com menor capacidade proliferativa.

Anoção de que vários tecidos e órgãos do corpo humano, como 0 fígado, músculo esquelético, pâncreas, e sistema nervoso, têm um estoque de células-tronco, com uma capacidade limitada de regeneração tecidual após injúria, é também recente9. Ainda mais recente é a idéia de que as células-tronco presentes nestes vários orgãos são não apenas multipotentes, no sentido de que podem gerar as células constitutivas daquele órgão específico, mas também pluripotentes, no sentido de que também podem gerar células de outros órgãos e tecidos. 0 primeiro relato desta propriedade das células-tronco adultas foi feito em 1998 por um grupo de cientistas italianos que estudaram a regeneração de músculo esquelético por células derivadas da medula óssea ${ }^{5}$. Embora 0 próprio músculo esquelético possua células-tronco, denominadas de células satélite, Giuliana Ferrari e colaboradores demonstraram ao injetar células de medula óssea de camundongos transgênicos em músculosesqueléticos lesados quimicamente em camundongos imunodeficientes, que as células medularesinjetadas eram capazes de se diferenciar em miócitos no ambiente muscular. Quando ao invés de injetar as células medulares na lesão muscular os autores faziam um transplante da medula óssea geneticamente marcada para oscamundongosimunodeficientes, havia uma migração das células medulares do animal doador para a área lesada no músculo esquelético do recipiente, demonstrando que, sob condições de injúria, células-tronco medulares adultas podem migrar para a região lesada e se diferenciar em músculo esquelético. Este trabalho estabeleceu duas novas idéias, a de que células-tronco de medula óssea podem dar origem a células musculares esqueléticas e a de que há migração das células medulares para regiões lesadas no músculo esquelético.

Em janeiro de 1999, cientistas liderados por Angelo Vescovi publicaram um trabalho no qual demonstrou-se que células-tronco neurais de camundongos adultos podem restaurar as células hematopoiéticas na medula óssea de camundongos que a tiveram destruída por irradiação ${ }^{2}$. Este trabalho representou uma verdadeira revolução nos conceitos até então vigentes, pois demonstrou que uma célula-tronco adulta derivada de um tecido reconhecido por seu alto grau de diferenciação e limitada capacidade proliferativa é capaz de seguir um programa de diferenciação completamente diverso se colocada em um ambiente adequado. Demonstrou também que as células-tronco adultas não estão limitadas no seu potencial de diferenciação pela sua origem embriológica; as células neurais têm origem no ectoderma e as sanguíneas no mesoderma embrionário.

Ainda em 1999, um grupo de cientistas suecos demonstrou que células-tronco neurais de camundongos adultos tem um potencial generalizado de diferenciação, podendo formar qualquer tipo celular, de músculo cardíaco a estômago, intestino, fígado e rim, quando injetadas em embriões de galinha e de camundongos ${ }^{3}$. A partir destes experimentos, consolidou-se a idéia de que células-tronco de organismos adultos retêm a capacidade proliferativa e de diferenciação em qualquer tipo 
celular do organismo, independente de seu tecido de origem, desde que cultivadas sob condições adequadas.

Esta pluripotencialidade das células-tronco adultas recoloca a questão da utilização terapêutica das células-tronco em bases totalmente novas. Não apenas nos vemos livres das questões ético-religiosas que cercam a utilização das células-tronco embrionárias na medicina, mas também nos livramos dos problemas de rejeição imunológica ao podermos utilizar célulastronco do próprio paciente adulto na regeneração de tecidos ou órgãos lesados.

\section{APLICAÇÕES DE TERAPIAS COM CÉLULAS-TRONCO EM CARDIOPATIAS}

Como mencionado acima, a constatação da pluripotencialidade das células-tronco abriu novas possibilidades terapêuticas. Nas cardiopatias em particular, 0 avanço das terapias celulares foi fantástico. Em casos de infarto do miocárdio, a injeção de célulastronco obtidas de medula óssea nas bordas da área lesada pela isquemia induziu o reparo do miocárdio lesado e causou a melhora funcional, inicialmente em estudos utilizando modelos animais $^{612}$, e mais recentemente, em pacientes ${ }^{14}{ }^{1920}$. Nos trabalhos experimentais, demonstrou-se que a melhora funcional estava associada a uma diminuição da área de fibrose, à formação de novos cardiomiócitos e a neovascularização ${ }^{6}{ }^{12} .0$ tratamento de animais com hormônios celulares, tais como o G-CSF e o SCF, capazes de induzir a mobilização de células de medula óssea para a periferia, foi também capaz de diminuir as lesões causadas posteriormente por um processo isquêmico no miocárdio ${ }^{13}$. Recentemente, a injeção direta de fatores de crescimento celular (IGF-1 e HGF) em corações de ratos lesados por agressão isquêmica, resultou em recuperação da função cardíaca e regeneração celular (Nadal-Ginard: comunicação pessoal), antevendo a possibilidade de terapias baseadas na simples injeção de fatores de estimulação e/ou crescimento celular.

Nossos estudos em modelos animais de cardiopatia isquêmica crônica demonstraram que células-tronco oriundas da medula óssea,

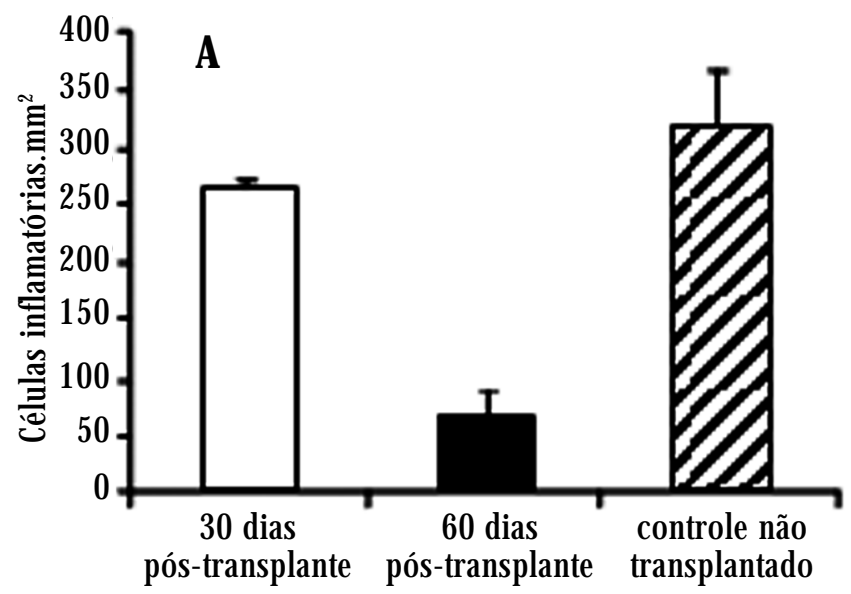

que são de fácil obtenção e que podem ser coletadas do próprio indivíduo a ser tratado (transplante autólogo), são eficazes no tratamento de insuficiência cardíaca de origem isquêmica, eindicaram um potencial da utilização desta terapia em outras cardiopatias ${ }^{11}$.

\section{TRATAMENTO DA CARDIOPATIA CHAGÁSICA CRÔNICA COM CÉLULAS-TRONCO}

Acardiopatia chagásica crônica, uma doença que afeta milhões de indivíduos na América Latina, é uma doença para a qual não há nenhum tratamento eficaz. Esta doença é caracterizada por uma resposta inflamatória que leva à destruição progressiva do miocárdio, resultando em cardiomegalia e insuficiência cardíaca congestiva, levando à morte dos indivíduos ${ }^{7}$. Embora os mecanismos de patogênese da doença ainda não estejam esclarecidos, a melhora da função cardíaca, como ocorre no reduzido número de pacientes que recebem transplante cardíaco, previne a acelerada evolução para o óbito. Portanto, uma terapia capaz de causar uma melhora da função cardíaca, e que seja mais accessível à população de cardiopatas chagásicos, em sua grande maioria de baixa renda, é de grande interesse.

Para testar a eficácia da terapia com células de medula óssea na cardiopatia chagásica, utilizamos 0 modelo experimental de camundongos isogênicos infectados pela cepa Colombiana de Trypanosoma cruzi. Células de medula óssea foram obtidas de camundongos normais e injetadas por via endovenosa em camundongos com cardiopatia chagásica crônica ${ }^{18}$. 0 grau de inflamação e de fibrose foi avaliado em vários períodos póstransplante. Camundongos transplantados tiveram uma melhora significativa na miocardite dois meses após o transplante, resultante de um aumento de apoptose nas células do infiltrado inflamatório (Figura 1a). Mais surpreendentemente, a fibrose existente no coração chagásico crônico diminuiu significativamente, indicando ser este um processo reversível (Figura 1b). Os efeitos da terapia com células de medula óssea foram duradouros, uma vez que 0 número de células inflamatórias e a área de fibrose permaneceram reduzidos até seis meses após o tratamento. Utilizando células de

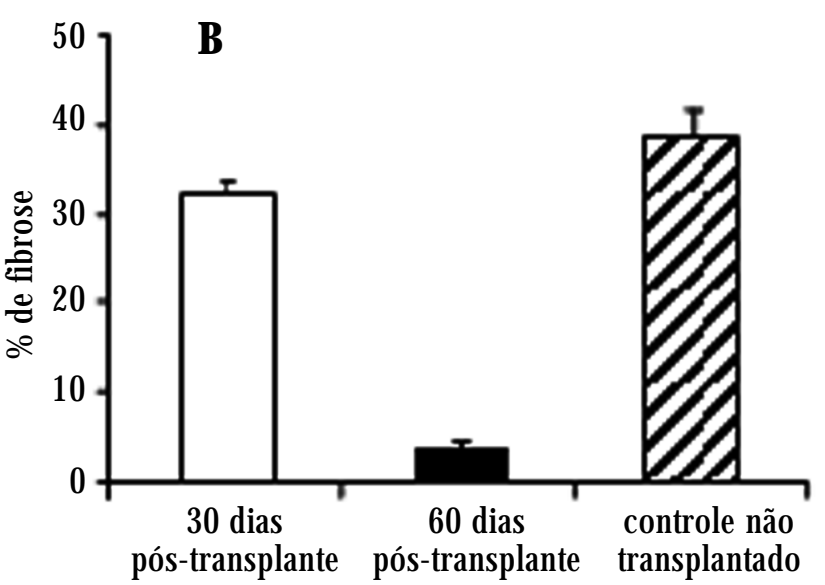

Figura 1 - Reducão da fibrose e inflamação no miocárdio chagásico crônico após o transplante de células de medula óssea. Grupos de camundongos BẢLB/C com infecção crônica (18 meses de infecção), não tratados ou transplantados com células de medula óssea singênicas ( $2 \times 10^{7}$ células por camundongo) foram sacrificados após 30 ou 60 dias de transplante. Secções do coração foram preparadas para avaliação histopatológica com coloração por hematoxilina/eosina para análise do infiltrado inflamatório (a) ou por tricrômio de Masson para quantificação de fibrose intersticial (b). Barras verticais representam os desvios padrões da media de 3-8 camundongos. 
medula óssea obtidas de camundongos chagásicos crônicos, infectados juntamente com os camundongos receptores, verificamos que estas células têm potencial semelhante de induzir a melhora da miocardite e diminuição de fibrose, sugerindo que 0 transplante autólogo de células de medula óssea em pacientes chagásicos poderia trazer resultados benéficos para estes pacientes.

Com a utilização de células de medula óssea obtidas de camundongos transgênicos para a proteína verde fluorescente (EGFP) ou para $\beta$-galactosidase de Escherichia coli (Gtrosa26), pode-se rastrear 0 destino de células-tronco injetadas em animais tratados. Ao avaliar o coração de camundongos chagásicos crônicos nos primeiros 15 dias após 0 transplante, pode-se verificar a presença de células transgênicas no miocárdio, indicando que parte destas células migram para 0 coração ( Figura 2) . Algumas destas células apresentaram morfologia de cardiomiócito e expressão de miosina, indicando a diferenciação das células de medula óssea transplantadas neste tipo celular (Figura 2b). No momento, estamos realizando experimentos para
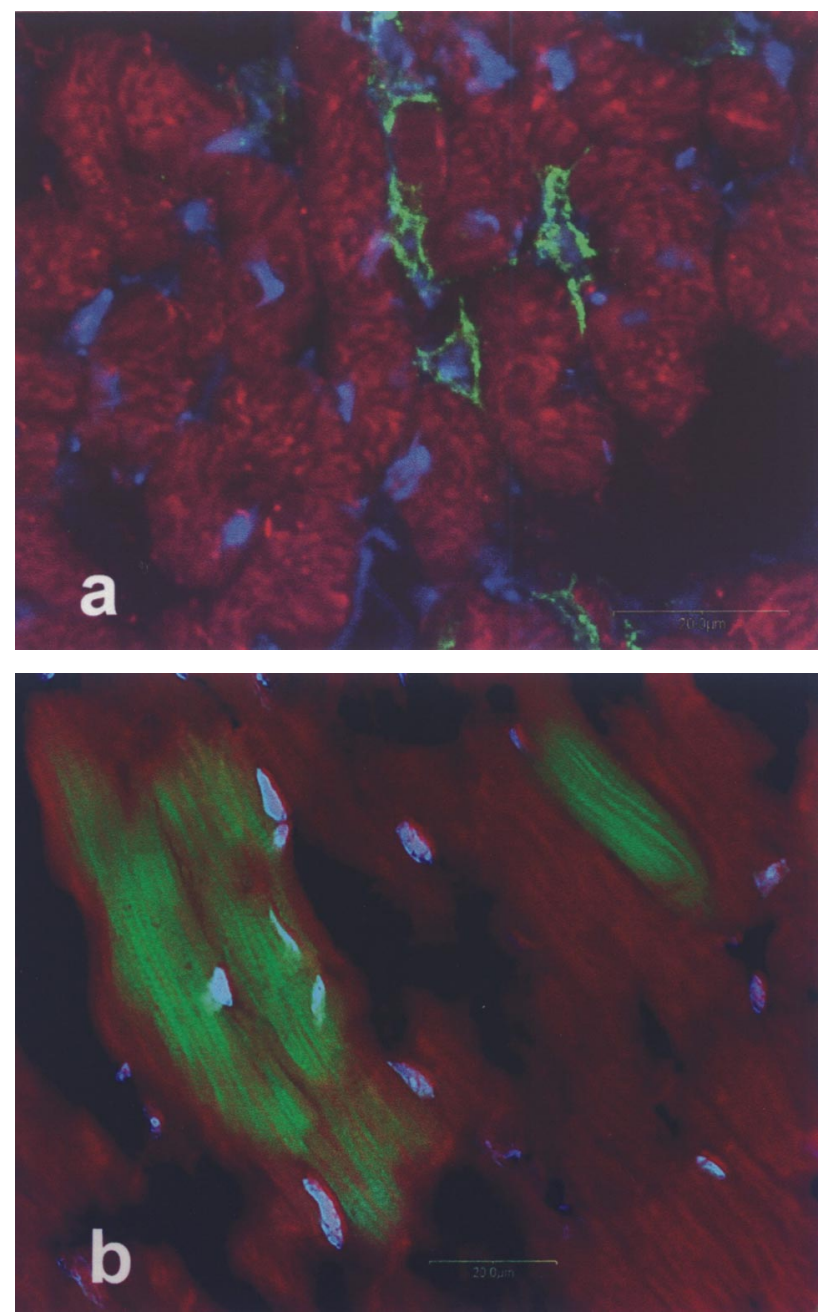

Figura 2 - Células de medula óssea injetadas em animais chagásicos crônicos migram para o miocárdio inflamado e se diferenciam em cardiomiócitos. a, Secção de coração de camundongo C57BL/6 chagásico crônico 3 dias após o transplante de células de medula óssea de camundongos transgênicos para $\beta$-Gal. a, Secção de coração de camundongo C57BL/ 6 chagásico crônico 15 dias após o transplante de células de medula óssea de camundongos transgênicos para EGFP. Secções foram coradas (em verde) com anti- $\beta$-Gal (a) ou antiGFP (b) e antimiosina (em vermelho), seguido do corante nuclear Hoechst 33258, e visualizadas em microscopio confocal. verificar se esta melhora a nível histopatológico se correlaciona com uma melhora da função cardíaca dos animais tratados com transplante de células de medula óssea. Uma possível sequêencia de eventos ocorridos no coração dos camundongos que receberam as células-tronco está resumida na Figura 3.

As causas da melhora da inflamação e dafibroseno modelo murino de cardiopatia chagásica após o transplante de células de medula óssea ainda não estão esclarecidas. 0 tratamento não causou alteração na carga parasitária, indicando que não há um efeito direto no parasita. Épossível, no entanto, quea resposta imune que promove a cardiopatia chagásica seja modulada pelo transplante de células de medula óssea. A observação de apoptose nas células do exudato inflamatório dos camundongos chagásicos transplantados, assim como a duração prolongada do efeito dos transplantes (até6 meses após o transplante) são indicações de que as células transplantadas podem estar alterando a resposta agressora ao coração. De fato, um trabalho recente demonstrou a atividade supressora de células da medula óssea em respostas imunes8.

Os dados experimentais no modelo murino nos levaram a testar, pela primeira vez no mundo, 0 uso de terapia com células de medula óssea em pacientes com insuficiência cardíaca de etiologia chagásica, em colaboração com Hospital Santa Izabel,

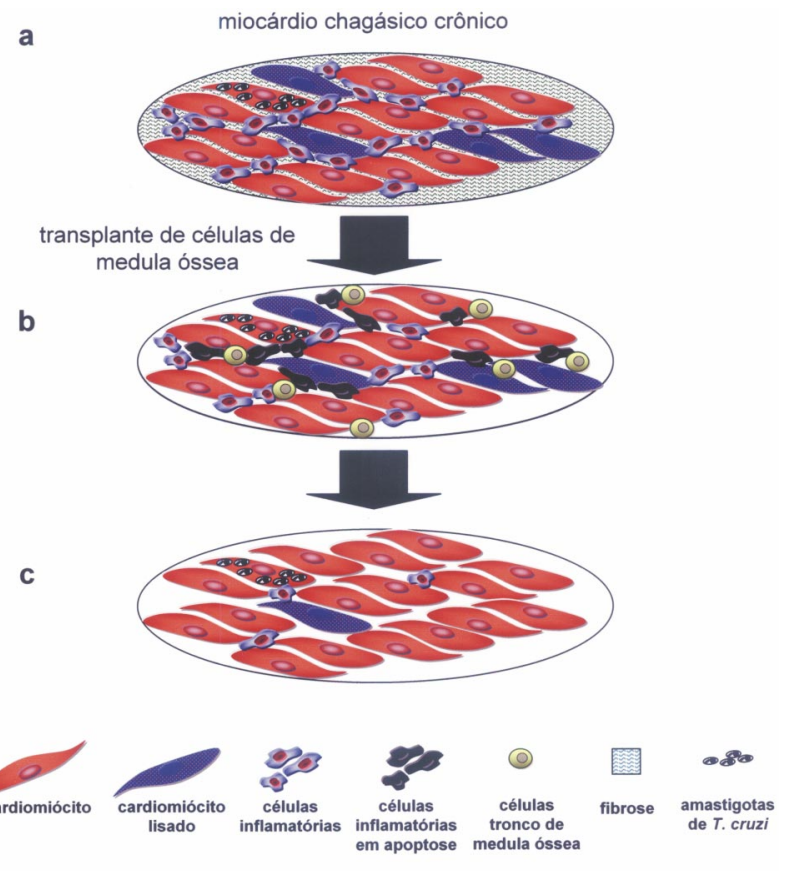

Figura 3 - Esquema do reparo tecidual resultante do transplante de células-tronco de medula óssea na cardiopatia chagásica crônica. O miocárdio chagásico crônico apresenta intensa inflamação que causa miocitólise e deposição de fibrose (a). Após o transplante de células- tronco, estas migram para o miocárdio inflamado e causam redução do número de células inflamatórias por indução de apoptose (através de mecanismos ainda desconhecidos) e diminuição da fibrose presentes na cardiopatia chagásica crônica (b). 0 reparo do tecido lesado (c) pode resultar da transformação de células- tronco (residentes no tecido cardíaco ou não) em novos cardiomiócitos e/ou estimulação da proliferação de cardiomiócitos já existentes, através de mecanismos ainda desconhecidos. A reducão da inflamacão previne ou diminui a ocorrência de novos eventos de miocitólise e a diminuição da produção de mediadores inflamatórios, que podem contribuir para a disfunção cardíaca e para a deposição de fibrose. 0 parasitismo residual no coração, assim como em outros tecidos, não é afetado por este processo. 
em Salvador, Bahia. Células de medula óssea são retiradas da crista ilíaca de pacientes chagásicos com insuficiência cardíaca graus III e IV da New York Heart Association, purificadas por centrifugação em gradiente de ficoll e injetadas lentamente através de um cateter nas coronárias. Os resultados iniciais demonstram que esta terapia é segura e exeqüível ${ }^{22}$. A eficácia deste tratamento está ainda sendo avaliada, 0 que requererá 0 tratamento de um número maior de individuos e um acompanhamento mais prolongado.

Diferentemente da lesão crônica resultante da isquemia do miocárdio, onde há pouca inflamação e cuja área é focal, a cardiopatia chagásica crônica apresenta intensa inflamação difusa por todo o miocárdio. 0 tratamento de lesões isquêmicas crônicas com células de medula óssea mostrou-se eficaz quando estas foram injetadas nas bordas da lesãa ${ }^{11}{ }^{12}$. Na cardiopatia chagásica, supomos que a resposta inflamatória persistente leve ao recrutamento das células de medula óssea transplantadas na periferia para 0 tecido cardíaco. A identificação dos fatores capazes de recrutar as células de medula óssea para o miocárdio poderá abrir novas possibilidades de tratamento para esta e para outras cardiopatias onde tais fatores não sejam produzidos.

É bem claro que pouco se sabe sobre os mecanismos de regeneração por células-tronco nesta ou em outras doenças, como por exemplo qual 0 tipo de célula na população de medula óssea que tem efeito no tratamento da cardiopatia chagásica. A identificação da(s) população( ões) responsável( is) pela melhora da miocardite é de grande interesse para 0 entendimento dos mecanismos de regeneração e para 0 desenvolvimento de estratégias mais refinadas de intervenção com células purificadas e/ou fatores celulares específicos. No entanto, uma vez que a injeção de células de medula óssea pouco purificadas ( somente em gradiente de ficoll) mostrou-se eficaz ao menos no modelo experimental, não se pode deixar de levar em conta 0 benefício potencial que a aplicação destas células pouco purificadas podem trazer aos pacientes que não têm nenhuma outra opção terapêutica que não seja 0 transplante cardíaco. A purificação de populações específicas certamente tornará 0 processo mais custoso, e não necessariamente mais eficiente.

A terapia com células de medula óssea não cura a doença de Chagas. Até onde observamos, não há alteração na carga parasitária ou na parasitemia dos animais tratados, indicando que ela não interfere na infecção pelo T. cruzi. Năo se sabe também se esta terapia tem efeito na resposta imune agressora ao coração. Esta é uma terapia com a qual se tenta reparar os danos causados durante anos ou até décadas de agressão ao miocárdio, resultante da doença de Chagas. 0 que se espera é que estes indivíduos possam conviver com o parasita sem sintomatologia, como ocorre com a maioria dos indivíduos infectados pelo $\mathrm{T}$. cruzi, na forma indeterminada da doença. A erradicação do parasita pelo tratamento com quimioterápicos é, portanto, uma meta desejada nestes indivíduos tratados com terapia celular, assim como em outros indivíduos infectados pelo T. cruzi. Neste cenário, ressalta-se 0 fato de que há mais de 25 anos não são produzidos novos fármacos com maior eficácia e menos efeitos colaterais do que as duas únicas drogas ainda utilizadas contra $0 \mathrm{~T}$. cruzi (benzonidazol e nifurtimox). A melhoria de função cardíaca nos indivíduos tratados com terapia celular talvez possibilite até mesmo a utilização das drogas já existentes, uma vez que devido à gravidade da doença e pela alta toxicidade dos medicamentos, em geral, a sua aplicação nem é recomendada.

\section{REFERÊNCIAS BIBLIOGRÁFICAS}

1. Beltrami AP, Barlucchi L, Torella D, Baker M, Limana F, Chimenti S, Kasahara H, Rota M, Musso E, Urbanek K, Leri A, Kajstura J, Nadal-Ginard B, Anversa P. Adult cardiac stem cells are multipotent and support myocardial regeneration. Cell 114:763-776, 2003.

2. Bjornson CR, Rietze RL, Reynolds B, Magli MC, Vescovi AL. Turning brain into blood: a hematopoietic fate adopted by adult neural stem cells in vivo. Science 283: 534-537, 1999.

3. Clarke DL, Johansson C, Wilbertz J, Veress B, Nilsson E, Karlström H, Lendahl U, Frisén J. Generalized potential of adult neural stem cells. Science 288: 1660-1663, 2000.

4. Evans MJ, Kaufman MH. Establishment in culture of pluripotential cells from mouse embryos. Nature 292: 154-156, 1981.

5. Ferrari G, Cusella G, Angelis D, Coletta M, Paolucci E, Stornaiuolo A, Cossu G, Mavilio F. Muscle Regeneration by Bone-Marrow Derived Myogenic Progenitors. Science 279: 1528-1530, 1998.

6. Jackson KA, Majka SM, Wang H, Pocius J, Hartley CJ, Majesky MW, Entman ML, Michael LH, Hirschi KK, Goodell MA. Regeneration of ischemic cardiac muscle and vascular endothelium by adult stem cells. Journal of Clinical Investigation 107:1395-1402, 2001

7. Köberle F. Chagas' disease and Chagas' syndromes: the pathology of American Trypanosomiasis. Advances in Parasitology 6:63-116, 1968.

8. Krampera M, Glennie S, Dyson J, Scott D, Laylor R, Simpson E, Dazzi F. Bone marrow mesenchymal stem cells inhibit the response of naive and memory antigen-specific T cells to their cognate peptide. Blood 101:3722-3729, 2003.

9. Krause DS. Plasticity of marrow-derived stem cells. Gene Therapy 9:754758, 2002.

10. Leri A, Kajstura J, Anversa P. Myocyte proliferation and ventricular remodeling. Journal of Cardiac Failure 8:518-525, 2002.

11. Olivares EL, Ribeiro VP, Werneck de Castro JP, Ribeiro KC, Mattos EC, Goldenberg RC, Mill JG, Dohmann HF, dos Santos RR, de Carvalho AC, Masuda MO. Bone marrow stromal cells improve cardiac performance in healed infarcted rat hearts. American Journal of Physiology - Heart and Circulatory Physiology 287:464-470, 2004.

12. Orlic D, Kajstura J, Chimenti S, Jakoniuk I, Anderson SM, Li B, Pickel J, McKay R, Nadal-Ginard B, Bodine DM, Leri A, Anversa P. Bone marrow cells regenerate infarcted myocardium. Nature 410:701-705, 2001.

13. Orlic D, Kajstura J, Chimenti S, Limana F, Jakoniuk I, Quaini F, NadalGinard B, Bodine DM, Leri A, Anversa P. Mobilized bone marrow cells repair the infarcted heart, improving function and survival. Proceedings of the National Academy of Science USA 98:10344-10349, 2001.

14. Perin EC, Dohmann HF, Borojevic R, Silva SA, Sousa AL, Mesquita CT, Rossi MI, Carvalho AC, Dutra HS, Dohmann HJ, Silva GV, Belem L, Vivacqua R, Rangel FO, Esporcatte R, Geng YJ, Vaughn WK, Assad JA, Mesquita ET, Willerson JT. Transendocardial, autologous bone marrow cell transplantation for severe, chronic ischemic heart failure. Circulation 107:2294-2302, 2003.

15. Pittenger MF, Mackay AM, Beck SC, Jaiswal RK, Douglas R, Mosca JD, Moorman MA, Simonetti DW, Craig S, Marshak DR. Multilineage potential of adult human mesenchymal stem cells. Science 284:143-147, 1999.

16. Quaini F, Urbanek K, Beltrami AP, Finato N, Beltrami CA, Nadal-Ginard B, Kajstura J, Leri A, Anversa P. Chimerism of the transplanted heart. New England Journal of Medicine 346:5-15, 2002.

17. Robertson E, Bradley A, Kuhen M, Evans, M. Germ-line transmission of genes introduced into cultured pluripotential cells by retroviral vector. Nature 323: 445-448, 1986.

18. Soares MBP, Lima RS, Rocha LL, Takyia CM, Pontes-de-Carvalho LC, Carvalho ACC, Ribeiro-dos-Santos R. Transplanted bone marrow cells repair 
heart tissue and reduce myocarditis in chronic chagasic mice. American Journal of Pathology 164:441-447, 2004.

19. Stamm C, Westphal B, Kleine HD, Petzsch M, Kittner C, Klinge H, Schumichen C, Nienaber CA, Freund M, Steinhoff G. Autologous bonemarrow stem-cell transplantation for myocardial regeneration. Lancet 361:45-46, 2003.

20. Strauer BE, Brehm M, Zeus T, Gattermann N, Hernandez A, Sorg RV, Kogler G, Wernet P. Intracoronary, human autologous stem cell transplantation for myocardial regeneration following myocardial infarction. Deutsche Medizinische Wochenschrift 126:932-938, 2001.

21. Turksen K. Embryonic Stem Cells: Methods and Protocols. In: Troy TC, Turksen K (eds) Methods in Molecular Biology, Humana Press, volume 185, 2002.

22. Vilas-Boas F, Feitosa GS, Soares MBP, Pinho Filho JA, Almeida A, Mota A, Carvalho HG, Oliveira ADD, Ribeiro dos Santos R. Transplante de células de medula óssea para 0 miocárdio em paciente com insuficiência cardíaca secundária à doença de Chagas. Relato de caso. Arquivos Brasileiros de Cardiologia 82:185-187, 2004. 